\title{
Effect of 22q11.2 deletion on bleeding and transfusion utilization in children with congenital heart disease undergoing cardiac surgery
}

\author{
Michelle K. Brenner', Shanelle Clarke², Donna K. Mahnke ${ }^{3}$, Pippa Simpson4, Rachel S. Bercovitz ${ }^{5}$, Aoy Tomita-Mitchell ${ }^{3}$, \\ Michael E. Mitchell ${ }^{3,6}$ and Debra K. Newman ${ }^{1,7,8}$
}

BACKGROUND: Postsurgical bleeding causes significant morbidity and mortality in children undergoing surgery for congenital heart defects (CHD). 22q11.2 deletion syndrome (DS) is the second most common genetic risk factor for CHD. The deleted segment of chromosome 22q11.2 encompasses the gene encoding glycoprotein (GP) Ib $\beta$, which is required for expression of the GPIb-V-IX complex on the platelet surface, where it functions as the receptor for von Willebrand factor (VWF). Binding of GPIb-V-IX to VWF is important for platelets to initiate hemostasis. It is not known whether hemizygosity for the gene encoding GPIb $\beta$ increases the risk for bleeding following cardiac surgery for patients with 22q11.2 DS.

METHODS: We performed a case-control study of 91 pediatric patients who underwent cardiac surgery with cardiopulmonary bypass from 2004 to 2012 at Children's Hospital of Wisconsin.

RESULTS: Patients with 22q11.2 DS had larger platelets and lower platelet counts, bled more excessively, and received more transfusion support with packed red blood cells in the early postoperative period relative to control patients.

CONCLUSION: Presurgical genetic testing for 22q11.2 DS may help to identify a subset of pediatric cardiac surgery patients who are at increased risk for excessive bleeding and who may require more transfusion support in the postoperative period.

A pproximately 40,000 children per year in the United States undergo cardiac surgery with cardiopulmonary bypass (CPB) for congenital heart defects (CHD) (1-4). Up to $40 \%$ of these patients experience excessive bleeding $(5,6)$, and coagulopathy associated with $\mathrm{CPB}$ has been found to be more severe in children than in adults (7). Recalcitrant post-CPB bleeding requires interventions that include transfusion of blood products, administration of recombinant activated factor VII, and surgical re-exploration, which are associated with increased morbidity and mortality (8-11). Identifying factors that contribute to excessive bleeding and transfusion risk in pediatric cardiac surgery patients may help to mitigate risks associated with poor outcomes in this patient population.

A potential contributing factor to bleeding in pediatric cardiac surgery patients is the underlying genetic defect responsible for CHD, which may affect hemostatic mechanisms. One such case is 22q11.2 deletion syndrome (DS), which is caused by the deletion of 1-3 megabases (Mb) of DNA (12), and occurs in 1 in 4,000 live births, making it the most common human microdeletion syndrome (13). The phenotype associated with 22q11.2 DS is complex; CHD, palatal anomalies, hypocalcemia, and learning difficulties are frequently observed (14). CHD associated with 22q11.2 DS is quite varied, but conotruncal abnormalities that include Tetralogy of Fallot, pulmonary atresia/ventricular septal defect, truncus arteriosus, subpulmonary ventricular septal defect, and interrupted aortic arch are the signature of cardiac malformations (15). CHD is found in $74 \%$ of patients with $22 \mathrm{q} 11.2 \mathrm{DS}$ and is the major cause of mortality in these patients (16). Overall, $5 \%$ of patients with CHD have 22q11.2 DS (13).

$G P I B B$ is a gene contained within the two stretches of DNA, one $3 \mathrm{Mb}$ in length and the other, a nested deletion, $1.5 \mathrm{Mb}$ in length, that are commonly deleted in patients with $22 \mathrm{q} 11.2$ DS (12) and is therefore expected to be deleted in $80-93 \%$ of these patients (17-20). GP1BB encodes glycoprotein (GP) Ib $\beta$, which is required for expression of the GPIb-V-IX complex on the platelet surface $(21,22)$. GPIb-V-IX is essential for platelets to adhere to von Willebrand factor and initiate hemostasis on damaged blood vessels in the arterial circulation (23). Failure of platelets to express functional GPIb-V-IX causes BernardSoulier syndrome, a severe autosomal-recessive bleeding disorder characterized by large platelets and decreased platelet counts (macrothrombocytopenia), and severely impaired

'Blood Research Institute, BloodCenter of Wisconsin, Milwaukee, Wisconsin; ${ }^{2}$ Department of Pediatrics, Division of Critical Care and Cardiology, Medical College of Wisconsin, Milwaukee, Wisconsin; ${ }^{3}$ Department of Surgery, Division of Cardiothoracic Surgery, Medical College of Wisconsin, Milwaukee, Wisconsin; ${ }^{4}$ Department of Pediatrics, Division of Quantitative Health Sciences, Medical College of Wisconsin, Milwaukee, Wisconsin; ${ }^{5}$ Medical Sciences Institute, BloodCenter of Wisconsin, Milwaukee, Wisconsin; ${ }^{6}$ Department of Cardiothoracic Surgery, Children's Hospital of Wisconsin, Milwaukee, Wisconsin; ${ }^{7}$ Department of Pharmacology and Toxicology, Medical College of Wisconsin, Milwaukee, Wisconsin; ${ }^{8}$ Department of Microbiology and Molecular Genetics, Medical College of Wisconsin, Milwaukee, Wisconsin; Correspondence: Debra Newman (debra.newman@bcw.edu)

Received 22 May 2015; accepted 31 July 2015; advance online publication 18 November 2015. doi:10.1038/pr.2015.216 
adhesion of platelets to damaged blood vessels (23). Patients with 22q11.2 DS have been described as "Bernard Soulier-like" in that they have an increased prevalence of macrothrombocytopenia (24-27), decreased levels of platelet surface expression of GPIb-V-IX and/or decreased levels of total platelet $\operatorname{GPIb} \beta(25,28)$, and platelet function defects $(25,28)$. In addition, patients with 22q11.2 DS have symptoms consistent with a mild hemostatic disorder such as easy bruising, epistaxis, and menorrhagia $(28,29)$. The extent to which patients with 22q11.2 DS bleed excessively in association with cardiac surgery is not known.

We investigated the association of 22q11.2 DS with bleeding and receipt of transfusions in pediatric patients undergoing cardiac surgery with CPB. The primary outcome of this study was excessive bleeding, which reflected the rate of chest tube output and controlled for the patient's total estimated blood volume. The secondary outcome of this study was transfusion utilization in the first $24 \mathrm{~h}$ postoperatively. We found that patients with 22q11.2 DS bled more excessively and received more transfusion support in the early postoperative period relative to matched patients without 22q11.2 DS. Our results suggest that genetic testing for 22q11.2 DS could help to identify a subset of pediatric patients with an elevated risk for bleeding and need for transfusion support in association with cardiac surgery.

\section{RESULTS}

\section{Patient Demographics and Surgical Experience}

The characteristics of study patients are shown in Table 1. Patients with 22q11.2 DS did not differ significantly from control patients with respect to age, gender, or weight. Consistent with previous reports (30-32), the majority of the patients in our study population (70\% of 22q11.2 DS patients and $67 \%$ of matched control patients) were diagnosed with Tetralogy of Fallot or truncus arteriosus. Two surgeons performed $\sim 85 \%$ of all surgeries for both case and control patients, and the two groups did not differ significantly with respect to the identity of the surgeon who performed the operation. Whole blood was used to prime the CPB pump for the majority of patients in both groups, and similar amounts of blood product were used to prime the pump for cases and controls. Patients with 22q11.2 DS and controls did not differ with respect to pre- or postoperative administration of medications that inhibit platelet function. Thus, patients with 22q11.2 DS and controls were administered prostaglandin E1 (19 and 18\%, respectively), aspirin (14 and 13\%, respectively), and enoxaparin (3 and $0 \%$, respectively) in the preoperative period. Only one patient, a control, was administered antiplatelet medication (aspirin) in the immediate postoperative period. With the exception of two control patients, all patients were administered the phosphodiesterase inhibitor milrinone in the immediate postoperative period. Previous studies have identified the lowest temperature experienced by patients during cardiac surgery and the amount of time spent on CPB as predictors of bleeding (33). In this study, cases and controls did not differ significantly with respect to either the average amount of time spent on CPB or
Table 1. Patient demographics and surgical experience

\begin{tabular}{|c|c|c|c|}
\hline Variable & $\begin{array}{l}\text { Control } \\
(N=55)\end{array}$ & $\begin{array}{l}22 q 11.2 \mathrm{DS} \\
(N=36)\end{array}$ & $\begin{array}{c}P \\
\text { value }\end{array}$ \\
\hline \multicolumn{4}{|l|}{ Demographic information } \\
\hline Age, days (median, range) & $120(5-4,588)$ & $55(6-4,320)$ & 0.73 \\
\hline Gender, male $(N, \%)$ & $33(60 \%)$ & $16(44 \%)$ & 0.20 \\
\hline Weight, kg (median, range) & $5.4(1.9-86.0)$ & $3.9(2.1-33.6)$ & 0.25 \\
\hline Cardiac anatomy diagnosis $(N, \%)$ & & & 0.88 \\
\hline $\begin{array}{l}\text { Tetralogy of Fallot-pulmonary } \\
\text { stenosis }\end{array}$ & $19(35 \%)$ & $11(31 \%)$ & \\
\hline $\begin{array}{l}\text { Tetralogy of Fallot-pulmonary } \\
\text { atresia }\end{array}$ & $5(9 \%)$ & $3(8 \%)$ & \\
\hline $\begin{array}{l}\text { Tetralogy of Fallot-pulmonary } \\
\text { atresia and MAPCAs }\end{array}$ & $4(7 \%)$ & $2(6 \%)$ & \\
\hline Truncus arteriosus & $7(13 \%)$ & $9(25 \%)$ & \\
\hline $\begin{array}{l}\text { Truncus arteriosus with } \\
\text { interrupted aortic arch }\end{array}$ & $2(3 \%)$ & $0(0 \%)$ & \\
\hline Interrupted aortic arch & $7(13 \%)$ & $5(13 \%)$ & \\
\hline Ventricular septal defect & $8(15 \%)$ & $4(11 \%)$ & \\
\hline Other & $3(5 \%)$ & $2(6 \%)$ & \\
\hline
\end{tabular}

Surgical information

Procedure $(N, \%)$

Tetralogy of Fallot, RV-PA conduit

Tetralogy of Fallot,

Truncus arteriosus repair

Interrupted aortic arch

repair

PA-VSD repair

VSD repair

Other

Surgeon $(N, \%)$

Surgeon $A$

Surgeon $B$

Surgeon C

Surgeon D

Surgeon E

Surgeon $\mathrm{F}$

Prime information

Priming product $(N, \%)$ Whole blood

Packed red blood cells and fresh frozen plasma

Clear prime only

Prime amount, $\mathrm{ml} / \mathrm{kg}$

(median, range)

$7(13 \%)$

$9(25 \%)$

$5(14 \%)$

$4(11 \%)$

$6(11 \%)$

4 (11\%)

$4(11 \%)$

0.34

$19(53 \%)$

12 (33\%)

$3(8 \%)$

$0(0 \%)$

$2(6 \%)$

$0(0 \%)$

$3(5 \%)$

0.80

Cardiopulmonary bypass time, $152(61-632) \quad 172(52-549) \quad 0.21$ minutes (median, range)

Lowest temperature during $\quad 27.6(16.3-33.4) 27.6(15.1-34.3) \quad 0.85$ surgery, ${ }^{\circ} \mathrm{C}$ (median, range)

MAPCA, major aortopulmonary collateral artery; PA-VSD, pulmonary atresia with ventricular septal defect; RV-PA, right ventricle to pulmonary artery; VSD, ventricular septal defect. 
the lowest temperature experienced during surgery. In addition, although hypocalcemia is often present in patients with 22q11.2 DS (14), neither preoperative (median $=4.76 \mathrm{mg} /$ $\mathrm{dl}$; range $=3.72-5.76 \mathrm{mg} / \mathrm{dl}$ ) nor postoperative (median $=$ $4.58 \mathrm{mg} / \mathrm{dl}$; range $=3.4-5.6 \mathrm{mg} / \mathrm{dl}$ ) ionized calcium levels in patients with 22q11.2 DS differed significantly from that of control patients (preoperative median $=4.84 \mathrm{mg} / \mathrm{dl}$; range $=$ $3.8-5.92 \mathrm{mg} / \mathrm{dl}$ and postoperative median $=4.84 \mathrm{mg} / \mathrm{dl}$; range $=3.48-5.76 \mathrm{mg} / \mathrm{dl})$.

\section{Hematologic Characteristics}

The results of standard clinical diagnostic laboratory tests of hemostatic function are shown in Table 2. Cases and controls did not differ significantly with respect to preoperative partial thromboplastin time, prothrombin time, or fibrinogen levels. Neither the pre- nor postoperative hematocrits of patients with 22q11.2 DS differed significantly from those of control patients. Patients with 22q11.2 DS had significantly larger platelets (mean platelet volume (MPV) of $10.4 \mathrm{vs}$. $7.5 \mathrm{fl}$, respectively) and a significantly lower platelet count prior to surgery relative to control patients $\left(235\right.$ vs. $305 \times 10^{3}$ platelets $/ \mu l$, respectively), as has been previously reported (24-27). In the postoperative period, platelet counts decreased significantly relative to preoperative values for both cases and controls, and the lower platelet counts observed prior to surgery in patients with 22q11.2 DS relative to controls persisted through postoperative day 1.

\section{Bleeding}

The primary outcome of this study was excessive bleeding in the first $12 \mathrm{~h}$ following surgery, which reflected the rate of chest tube output and controlled for the patient's total estimated blood volume. We found that approximately twice as many cases $(15 / 36,42 \%)$ as controls $(11 / 55,20 \%)$ met the criteria for excessive bleeding, and this difference was statistically

Table 2. Hematologic information

\begin{tabular}{|c|c|c|c|}
\hline $\begin{array}{l}\text { Variable } \\
\text { (median, range) }\end{array}$ & Control $(N=55)$ & $22 q 11.2 \mathrm{DS}(N=36)$ & $P$ value \\
\hline \multicolumn{4}{|l|}{ Preoperative values } \\
\hline PTT, seconds & $33.7(24.1-119.1)^{a}$ & $35.2(24.0-200.0)^{\mathrm{b}}$ & 0.74 \\
\hline PT, seconds & $13.1(11.1-18.6)^{a}$ & $13.3(11.3-17.2)^{b}$ & 0.48 \\
\hline Fibrinogen, mg/dl & $266(115-503)^{a}$ & $284(125-452)^{\mathrm{b}}$ & 0.17 \\
\hline Hematocrit, \% & $41.7(28.0-57.3)$ & $39.8(30.2-52.1)$ & 0.10 \\
\hline $\begin{array}{l}\text { Mean platelet } \\
\text { volume, fl }\end{array}$ & $7.5(5.7-11.1)$ & $10.4(6.4-15.2)$ & $<0.0001$ \\
\hline $\begin{array}{l}\text { Platelet count, } \times \\
10^{3} / \mu \mathrm{l}\end{array}$ & $305(95-688)$ & $235(54-506)$ & 0.0006 \\
\hline \multicolumn{4}{|c|}{ Postoperative values: day 1} \\
\hline Hematocrit, \% & $40.4(25.6-56.2)$ & $41.3(27.3-54.1)$ & 0.95 \\
\hline $\begin{array}{l}\text { Platelet count, } \times \\
10^{3} / \mu \mathrm{l}\end{array}$ & $183(73-405)^{*}$ & $135(69-506)^{*}$ & 0.001 \\
\hline \multicolumn{4}{|c|}{$\begin{array}{l}\text { Bold font depicts } P \text { value }<0.05 \text {. } \\
\text { PT, prothrombin time; PTT, partial thromboplastin time. } \\
\text { a } n=53 .{ }^{b} n=35 .{ }^{*} \text { Significant difference }(P<0.0001) \text { relative to preoperative platelet } \\
\text { count. }\end{array}$} \\
\hline
\end{tabular}

significant (Table 3 ). Total chest tube output, the frequency with which bleeding was described in the operative note, and the frequency with which patients required emergent re-exploration did not differ significantly between control patients and patients with 22q11.2 DS (Table 3). Notably, although differences between cases and controls did not achieve statistical significance at a $P$ value of $<0.05$ for the latter two outcomes, bleeding was described in the operative note more than twice as frequently for patients with 22q11.2 DS (9/36, 25\%) than for control patients $(6 / 55,11 \%)$, and emergent re-exploration was required about $50 \%$ more frequently in patients with $22 \mathrm{q} 11.2$ DS $(6 / 36,17 \%)$ than in control patients $(6 / 55,11 \%)$.

\section{Transfusion Support}

The secondary outcome of this study was transfusion utilization, since increased use of transfused blood products following surgery can be interpreted as an indication of excessive bleeding. We therefore compared the volumes of blood products with which patients were transfused and the incidence of transfusion during the perioperative period and during the first $24 \mathrm{~h}$ postoperatively (Table 4 ). In the perioperative period, cases and controls did not differ significantly with respect to the volumes with which they were transfused or the incidence of transfusion for any blood product. In the first $24 \mathrm{~h}$ postoperatively, however, patients with 22q11.2 DS were significantly more likely to receive a packed red blood cell (PRBC) transfusion $(78 \%)$ and were transfused with a significantly larger volume of PRBC $(14 \mathrm{ml} / \mathrm{kg})$ relative to control patients $(51 \%$ and $2 \mathrm{ml} / \mathrm{kg}$, respectively).

Table 3. Bleeding

\begin{tabular}{|c|c|c|c|}
\hline Variable & Control $(N=55)$ & $\begin{array}{c}22 q 11.2 \mathrm{DS} \\
(N=36)\end{array}$ & $P$ value \\
\hline $\begin{array}{l}\text { Excessive bleeding: } 0-12 \mathrm{~h} \\
\text { postoperative }(N, \%)\end{array}$ & & & 0.03 \\
\hline No & $44(80 \%)$ & $21(58 \%)$ & \\
\hline Yes & $11(20 \%)$ & $15(42 \%)$ & \\
\hline \multicolumn{4}{|l|}{$\begin{array}{l}\text { Chest tube output, } \mathrm{ml} / \mathrm{kg} \\
\text { (median, range) }\end{array}$} \\
\hline ICU: 0-12 h postoperative & $25(2-164)$ & $32(3-66)$ & 0.29 \\
\hline ICU: $12-24 \mathrm{~h}$ postoperative & $9(0-191)$ & $15(1-51)$ & 0.17 \\
\hline ICU: $0-24 \mathrm{~h}$ postoperative & $36(5-355)$ & $46(5-105)$ & 0.18 \\
\hline $\begin{array}{l}\text { Bleeding described in the } \\
\text { operative note }(N, \%)\end{array}$ & & & 0.09 \\
\hline No & 49 (89\%) & $27(75 \%)$ & \\
\hline$Y_{e s}{ }^{a}$ & $6(11 \%)$ & $9(25 \%)$ & \\
\hline $\begin{array}{l}\text { Required emergent } \\
\text { re-exploration }(N, \%)\end{array}$ & & & 0.53 \\
\hline No & 49 (89\%) & $30(83 \%)$ & \\
\hline Yes & $6(11 \%)$ & $6(17 \%)$ & \\
\hline
\end{tabular}

Bold font depicts $P$ value $<0.05$

aHematologic defect was identified as a possible cause of bleeding in the surgical notes of $3 / 6(50 \%)$ of control and 7/9 (78\%) of 22q11.2 DS patients. 
22q11.2 DS as a Predictor of Bleeding and Transfusion Support A multivariable conditional logistic regression analysis was performed to identify variables that correlated with either excessive bleeding in the first $12 \mathrm{~h}$ after surgery or receipt of a PBRC transfusion in the first $24 \mathrm{~h}$ after surgery. Patients with 22q11.2 DS were approximately four times more likely than were control patients to bleed excessively in the first $12 \mathrm{~h}$ postoperatively (odds ratio $=4.21 ; 95 \%$ confidence interval $=1.12$ $15.86 ; P=0.0339$ ). In addition, the presence of $22 \mathrm{q} 11.2 \mathrm{DS}$ was the only variable that correlated with transfusion with PRBC in the first $24 \mathrm{~h}$ following surgery, and patients with $22 \mathrm{q} 11.2$ DS were three times more likely than were control patients to receive a $\mathrm{PRBC}$ transfusion in this time period following surgery $($ odds ratio $=3.00 ; 95 \%$ confidence interval $=1.05-8.60$; $P=0.0399)$.

Thus far, our results indicate that, relative to control patients, 22q11.2 DS patients were characterized by platelet defects including a higher MPV and a lower platelet count (Table 2) and postsurgical bleeding complications, including a higher

Table 4. Transfusion experience

\begin{tabular}{|c|c|c|c|}
\hline Variable & $\begin{array}{l}\text { Control } \\
(N=55)\end{array}$ & $\begin{array}{c}22 q 11.2 \mathrm{DS} \\
(N=36)\end{array}$ & $P$ value \\
\hline \multicolumn{4}{|c|}{ Transfusions received in the OR during the perioperative period } \\
\hline \multicolumn{4}{|c|}{ Quantity transfused, $\mathrm{ml} / \mathrm{kg}$ (median, range) } \\
\hline Packed red blood cells & $0(0-172)^{a}$ & $7(0-193)^{b}$ & 0.19 \\
\hline Fresh frozen plasma & $8(0-147)^{c}$ & $10(0-98)^{d}$ & 0.53 \\
\hline Platelets & $6(0-38)^{a}$ & $10(0-43)$ & 0.30 \\
\hline Cryoprecipitate & $0(0-13)$ & $0(0-28)$ & 0.32 \\
\hline Whole blood & $0(0-18)^{\mathrm{e}}$ & $0(0-9)$ & 0.59 \\
\hline \multicolumn{4}{|c|}{ Incidence of transfusion $(N, \%)$} \\
\hline Packed red blood cells & $22(43 \%)^{\mathrm{a}}$ & $19(56 \%)^{b}$ & 0.28 \\
\hline Fresh frozen plasma & $29(56 \%)^{c}$ & $21(60 \%)^{d}$ & 0.83 \\
\hline Platelets & $30(59 \%)^{\mathrm{a}}$ & $25(69 \%)$ & 0.37 \\
\hline Cryoprecipitate & $9(16 \%)$ & $9(25 \%)$ & 0.42 \\
\hline Whole blood & $8(15 \%)^{e}$ & $4(11 \%)$ & 0.76 \\
\hline \multicolumn{4}{|c|}{ Transfusions received in the ICU $0-24 \mathrm{~h}$ postoperatively } \\
\hline \multicolumn{4}{|c|}{ Quantity transfused, $\mathrm{ml} / \mathrm{kg}$ (median, range) } \\
\hline Packed red blood cells & $2(0-86)$ & $14(0-47)$ & 0.02 \\
\hline Fresh frozen plasma & $11(0-104)$ & $9(0-66)$ & 0.75 \\
\hline Platelets & $0(0-59)$ & $0(0-27)$ & 0.86 \\
\hline Cryoprecipitate & $0(0-9)$ & $0(0-12)$ & 0.34 \\
\hline Whole blood & $0(0-49)$ & $0(0-20)$ & 0.83 \\
\hline \multicolumn{4}{|c|}{ Incidence of transfusion $(N, \%)$} \\
\hline Packed red blood cells & $28(51 \%)$ & $28(78 \%)$ & 0.01 \\
\hline Fresh frozen plasma & $36(65 \%)$ & $25(69 \%)$ & 0.82 \\
\hline Platelets & $19(35 \%)$ & $13(36 \%)$ & 1.00 \\
\hline Cryoprecipitate & $2(4 \%)$ & $3(8 \%)$ & 0.38 \\
\hline Whole blood & $2(4 \%)$ & $1(3 \%)$ & 1.00 \\
\hline
\end{tabular}

Bold font depicts $P$ value $<0.05$.

$\mathrm{ICU}$, intensive care unit.

${ }^{a} n=51 \cdot{ }^{b} n=34 \cdot{ }^{c} n=52 \cdot{ }^{d} n=35,{ }^{e} n=54$. incidence of excessive bleeding (Table 3) and both a higher incidence and a larger volume of PRBC transfusion (Table 4). To determine the clinical significance of the platelet defects associated with $22 \mathrm{q} 11.2 \mathrm{DS}$, we evaluated the extent to which MPV and platelet count correlated with postsurgical bleeding and transfusion support in this patient population. We found that MPV correlated significantly with the likelihood of PBRC transfusion but not with excessive bleeding or with the volume of PRBCs transfused. Platelet count did not correlate with either bleeding or increased transfusion support in the 22q11.2 DS patient population. In a simple regression model, every unit increase in MPV was associated with an increased likelihood of receipt of a PRBC transfusion by a 22q11.2 DS patient (odds ratio $=2.43 ; 95 \%$ confidence interval $=1.34-5.62$; $P=0.0131)$. A multivariable logistic regression analysis revealed that MPV was the only variable that correlated with receipt of a PRBC transfusion in the first $24 \mathrm{~h}$ following cardiac surgery for patients with 22q11.2 DS (odds ratio $=3.80 ; 95 \%$ confidence interval $=1.44-10.03 ; P=0.0071)$. Interestingly, 24 of the 25 (96\%) 22q11.2 DS patients with a preoperative MPV of $>9.5 \mathrm{fl}$ received a PRBC transfusion in the first 24 hours following cardiac surgery, whereas this was true of only 4 of the 11 (36\%) 22q11.2 DS patients with an MPV $<9.5 \mathrm{fl}$ (Figure 1a). We generated a receiver-operator characteristic curve to assess the relationship between MPV and postsurgical receipt of a PRBC transfusion for patients with 22q11.2 DS. The receiveroperator characteristic curve had an area under the curve of 0.8705 with a sensitivity of $82 \%$ and a specificity of $88 \%$ at an MPV of $9.5 \mathrm{fl}$ (Figure 1b,c), reflecting a strong relationship between MPV and postsurgical receipt of a PRBC transfusion for patients with 22q11.2 DS.

\section{DISCUSSION}

We report results of a case-control analysis of bleeding and transfusion experience in pediatric patients with $22 \mathrm{q} 11.2$ DS who underwent cardiac surgery with CPB for CHD. We found that, relative to other CHD patients, patients with 22q11.2 DS had a higher incidence of excessive bleeding and received more transfusion support in the early postoperative period. Although this study was a retrospective analysis performed at a single institution and must therefore be interpreted with caution, the results are consistent with the pathophysiology associated with GPIBB hemizygosity. If validated, our results support presurgical genetic testing for 22q11.2 DS and determination of MPV in patients with 22q11.2 DS. Furthermore, platelet transfusions, either prophylactic or in association with bleeding, should be considered for pediatric patients with 22q11.2 DS, particularly those with high MPVs, who undergo cardiac surgery for congenital heart defects.

This study is the first to associate 22q11.2 DS with increased bleeding and transfusion support in children who undergo cardiac surgery. Numerous factors have previously been shown to contribute to the need for transfusion support and/or incidence of significant bleeding in these children. These factors include conditions associated with $\mathrm{CPB}$, such as contact of 
blood with the artificial surfaces of the bypass unit (34), hemodilution of platelets and coagulation factors $(7,33,35,36)$, hypothermia induced during surgery $(33,37)$, and length of time on bypass $(33,37)$. Patient-specific factors such as age and weight have also been found to contribute to bleeding in children following cardiac surgery $(33,37)$. The case-control design of this study, which enabled patients with 22q11.2 DS to be matched with control patients on the basis of age, cardiac anatomy, and surgical procedure, eradicated significant differences between patient populations with respect to weight, volume of blood products used to prime the bypass pump (which determines the extent of hemodilution), the lowest temperature achieved during surgery, and the length of time on bypass. Controlling for these factors may have been important in allowing 22q11.2 DS to emerge as a factor associated with increased bleeding and transfusion in pediatric cardiac surgery patients.

The major limitations of this study are that it is retrospective in nature and performed at a single institution. An additional limitation is that, due to its retrospective nature, this study does not allow us to determine why patients with $22 \mathrm{q} 11.2$ DS required more transfusion support and bled more following cardiac surgery than did patients with other causes of CHD. A multi-institutional prospective study is necessary to validate the findings of this single institution retrospective analysis and elucidate the mechanisms underlying abnormal hemostasis and defective platelet function in patients with 22q11.2 DS.

\section{METHODS}

\section{Study Population}

This study was a case-control design in which cardiac surgery patients with 22q11.2 DS were matched on the basis of age, cardiac anatomy, and surgical procedure with 1-2 patients with another cause of CHD. The records of patients who underwent cardiac surgery with CPB at Children's Hospital of Wisconsin between November 2004 and June 2012 were evaluated to identify subjects for inclusion in the study. All patients considered for enrollment had been tested for the $22 \mathrm{q} 11.2$ deletion using a multiplexed quantitative real-time PCR assay to determine the copy number of the TBX1 gene, which is typically deleted in this disorder (38). From a total of 136 potentially eligible patients, 45 patients were excluded because they did not meet inclusion criteria, could not be matched with a suitable control patient, or were missing an essential piece of data (Figure 2). The final study population included 91 subjects, 36 of whom had 22q11.2 DS and 55 of whom were matched controls. Records were reviewed in strict compliance with a study protocol that was approved by the Children's Hospital of Wisconsin institutional review board. The need for informed consent was waived due to the retrospective nature of the study.

\section{Outcomes and Definitions}

Data related to patient demographics, surgical experience, hematologic characteristics, transfusion experience, and bleeding were recovered from the medical record. Hematologic, bleeding, and transfusion data were grouped on the basis of the time period relative to surgery from which they were collected. The perioperative period for this study is defined as the time period from removal of the patient from CPB until admission into the cardiac intensive care unit. The postoperative period spanned the first $24 \mathrm{~h}$ spent in the cardiac intensive care unit.

The primary outcome of this study was excessive bleeding in the first $12 \mathrm{~h}$ postoperatively. Patients were considered to have had excessive bleeding if they met any of the following conditions: (i) chest tube

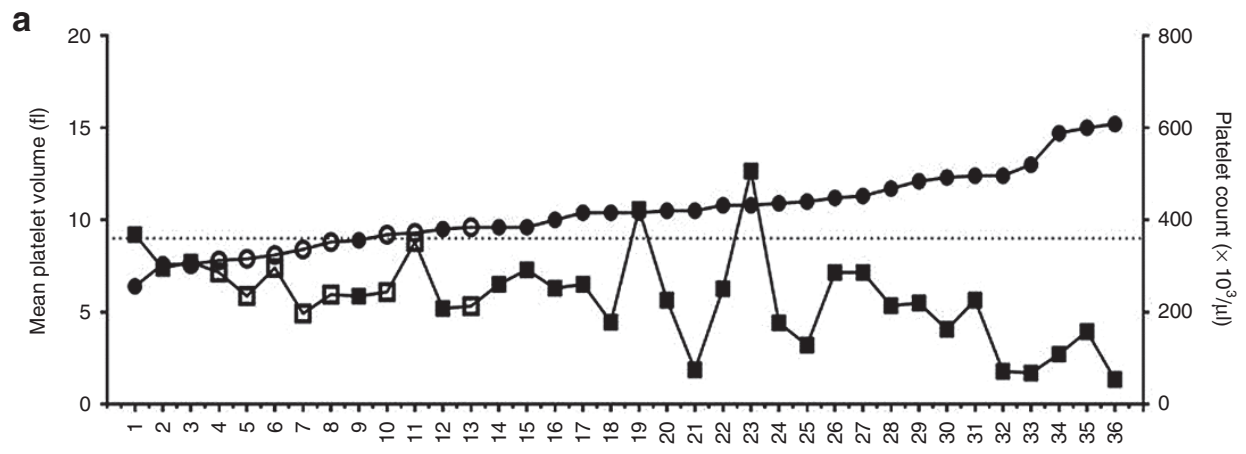

Patient ID

b

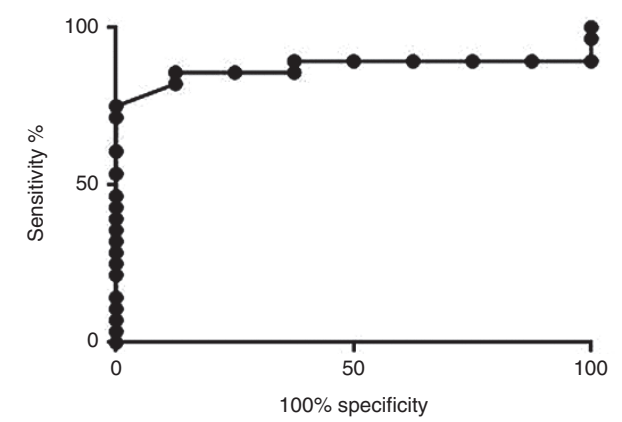

C

\begin{tabular}{|c|c|c|}
\hline MPV (fl) & Sensitivity & Specificity \\
\hline 6.0 & $96 \%$ & $0 \%$ \\
\hline 6.5 & $96 \%$ & $0 \%$ \\
\hline 7.0 & $96 \%$ & $0 \%$ \\
\hline 7.5 & $89 \%$ & $0 \%$ \\
\hline 8.0 & $89 \%$ & $25 \%$ \\
\hline 8.5 & $89 \%$ & $50 \%$ \\
\hline 9.0 & $86 \%$ & $63 \%$ \\
\hline 9.5 & $82 \%$ & $88 \%$ \\
\hline 10.0 & $71 \%$ & $100 \%$ \\
\hline 10.5 & $61 \%$ & $100 \%$ \\
\hline 11.0 & $39 \%$ & $100 \%$ \\
\hline 11.5 & $32 \%$ & $100 \%$ \\
\hline 12.0 & $25 \%$ & $100 \%$ \\
\hline
\end{tabular}

Figure 1. Increased mean platelet volume (MPV) is associated with increased likelihood of receiving a packed red blood cell (PRBC) transfusion following cardiac surgery among patients with 22q11.2 deletion syndrome (DS). (a) Preoperative MPV $(\bullet, 0)$ and platelet count $(\boldsymbol{\square}, \square)$ of individual patients with 22q11.2 DS who were $(\bullet, \square)$ or were not $(0, \square)$ transfused with PRBC in the first $24 \mathrm{~h}$ after cardiac surgery are plotted in ascending order of MPV. The dotted line corresponds to an MPV of $9.5 \mathrm{fl}$. (b) Receiver-operator characteristic (ROC) curve of the relationship between MPV and postsurgical PRBC transfusion. (c) Sensitivity and specificity analysis of ROC curve at specific MPVs. 


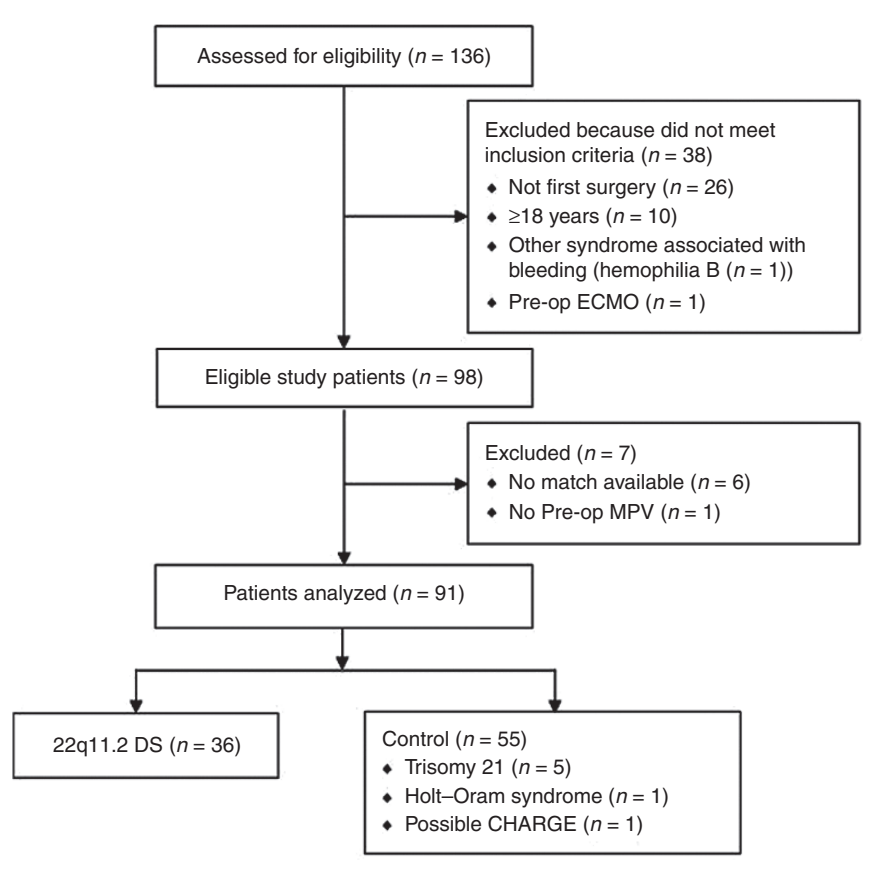

Figure 2. Flowchart of patients included in the study. A total of 136 patients who underwent cardiac surgery with cardiopulmonary bypass from November 2004 to June 2012 at Children's Hospital of Wisconsin were assessed for eligibility. Thirty-eight patients were excluded because they did not meet inclusion criteria, either because the data available for them were associated with a second or subsequent surgery for $\mathrm{CHD}$ $(n=26)$ or because they were older than $18 \mathrm{y}$ of age $(n=10)$, had hemophilia B $(n=1)$, or had been maintained on extracorporeal membrane oxygenation prior to surgery $(n=1)$. Seven additional patients were excluded from analysis because a suitable matching patient was unavailable $(n=6)$ or because the preoperative mean platelet volume was missing $(n=1)$. Ninety-one patients were included in the final analysis, including 36 patients with 22q11.2 DS and 55 matched control patients.

output of $\geq 20 \%$ of estimated blood volume in the first $2 \mathrm{~h}$, (ii) $\geq 20 \%$ of estimated blood volume in hours $2-6$, or (iii) $\geq 30 \%$ of estimated blood volume in hours $6-12$ in the cardiac intensive care unit $(39,40)$. Secondary outcomes included (i) total chest tube output during the first 24-h period postoperatively, (ii) transfusion experience, specifically the amount of blood product with which patients were transfused (in $\mathrm{ml} / \mathrm{kg}$ ) or the incidence of transfusion in the perioperative period and in the first $24 \mathrm{~h}$ postoperatively, (iii) the frequency with which patients required emergent re-exploration, and (iv) the extent to which bleeding was described in the operative note. Of note, there was no institutional transfusion protocol, and all transfusion decisions were made at the discretion of the attending physician.

\section{Statistical Analysis}

The cohort and outcomes were described using descriptive statistics. Continuous variables were described using the median and range and compared using the Wilcoxon rank sum test. Categorical variables, described as number and percentage, were compared using fisher's exact test. A multivariable conditional logistic regression (patients matched by age, cardiac anatomy, and surgical procedure) with the endpoint of having excessive bleeding or receiving a PRBC transfusion in the first $24 \mathrm{~h}$ postoperatively was performed using a stepwise selection method. The presence or absence of a diagnosis of $22 \mathrm{q} 11.2$ DS was assessed in the model as were other potential confounders to bleeding, including the length of time on $\mathrm{CPB}$, lowest temperature achieved during surgery, preoperative partial thromboplastin time, preoperative prothrombin time, preoperative fibrinogen, preoperative hematocrit, preoperative platelet count, preoperative MPV, presence of a genetic anomaly other than 22q11.2 DS, and surgeon performing the operation. A multivariable logistic regression with the same endpoints was also performed for patients with 22q11.2 DS to determine patient characteristics associated with increased postoperative bleeding and transfusion support. Cofounding variables included weight, gender, cardiac anatomy, surgical procedure, the length of time on $\mathrm{CPB}$, lowest temperature achieved during surgery, preoperative partial thromboplastin time, preoperative prothrombin time, preoperative fibrinogen, preoperative hematocrit, preoperative platelet count, preoperative MPV, and surgeon performing the operation. The strength of the association between MPV and PRBC transfusion in the first $24 \mathrm{~h}$ after cardiac surgery was examined using a receiver operating characteristics curve analysis. For varying MPV thresholds, sensitivity and specificity was calculated. Differences between patients with 22q11.2 DS and controls were considered to be statistically significant at a $P$ value $<0.05$. All analyses were performed using SAS version 9.3 (SAS Institute, Cary, NC). Graphs were created using Graphpad Prism 6 (Graphpad Software, LaJolla, CA).

\section{ACKNOWLEDGMENTS}

The authors thank Tao Wang for help with statistical analyses and PCTHRC members D. Woodrow Benson, Jim Tweddell, Ron Woods, Jake Scott, Rob Neibler, Bob Montgomery, Alan Mast, Susan Maroney, Julie Slicker, Rowena Punzalan, and Paul Scott for helpful study design and editorial comments. The authors are indebted to Roy Silverstein for helpful editorial comments.

\section{STATEMENT OF FINANCIAL SUPPORT}

This work was supported by funds awarded from the Medical College of Wisconsin (Milwaukee, WI) and Children's Hospital of Wisconsin (Milwaukee, WI) to the Pediatric Cardiac Thrombosis and Hemostasis Research Center (PCTHRC), Milwaukee, WI. The study was also supported in part by funding from the National Center for Advancing Translational Sciences, National Institutes of Health (8UL1TR000055; Bethesda, MD) and in part by the Audrey Hohenwalter Foundation (Milwaukee, WI).

Disclosure: A.T.-M. and M.E.M. have significant financial interest in Ariosa Diagnostics, a molecular diagnostics company. Ariosa Diagnostics had no role in the study design, data collection and analysis, decision to publish, or preparation of the manuscript. The other authors declare no conflict of interest.

\section{REFERENCES}

1. Reller MD, Strickland MJ, Riehle-Colarusso T, Mahle WT, Correa A. Prevalence of congenital heart defects in metropolitan Atlanta, 1998-2005. J Pediatr 2008;153:807-13.

2. Hoffman JI, Kaplan S. The incidence of congenital heart disease. J Am Coll Cardiol 2002;39:1890-900.

3. Martin JA, Hamilton BE, Ventura SJ, et al. Births: final data for 2009. Natl Vital Stat Rep 2011;60:1-70.

4. Moller JH, Taubert KA, Allen HD, Clark EB, Lauer RM. Cardiovascular health and disease in children: current status. A Special Writing Group from the Task Force on Children and Youth, American Heart Association. Circulation 1994;89:923-30.

5. Ranucci M, Carlucci C, Isgrò G, Baryshnikova E. A prospective pilot study of platelet function and its relationship with postoperative bleeding in pediatric cardiac surgery. Minerva Anestesiol 2012;78:556-63.

6. Moganasundram S, Hunt BJ, Sykes K, et al. The relationship among thromboelastography, hemostatic variables, and bleeding after cardiopulmonary bypass surgery in children. Anesth Analg 2010;110:995-1002.

7. Kern FH, Morana NJ, Sears JJ, Hickey PR. Coagulation defects in neonates during cardiopulmonary bypass. Ann Thorac Surg 1992;54:541-6.

8. Gill R, Herbertson M, Vuylsteke A, et al. Safety and efficacy of recombinant activated factor VII: a randomized placebo-controlled trial in the setting of bleeding after cardiac surgery. Circulation 2009;120:21-7.

9. Székely A, Cserép Z, Sápi E, et al. Risks and predictors of blood transfusion in pediatric patients undergoing open heart operations. Ann Thorac Surg 2009;87:187-97.

10. Moulton MJ, Creswell LL, Mackey ME, Cox JL, Rosenbloom M. Reexploration for bleeding is a risk factor for adverse outcomes after cardiac operations. J Thorac Cardiovasc Surg 1996;111:1037-46.

11. Unsworth-White MJ, Herriot A, Valencia O, et al. Resternotomy for bleeding after cardiac operation: a marker for increased morbidity and mortality. Ann Thorac Surg 1995;59:664-7. 
12. Kobrynski LJ, Sullivan KE. Velocardiofacial syndrome, DiGeorge syndrome: the chromosome 22q11.2 deletion syndromes. Lancet 2007;370:1443-52.

13. Wilson DI, Burn J, Scambler P, Goodship J. DiGeorge syndrome: part of CATCH 22. J Med Genet 1993;30:852-6.

14. GeneReviews. 22q11.2 Deletion Syndrome, 2013. (http://www.ncbi.nlm. nih.gov/books/NBK1523/.)

15. Khositseth A, Tocharoentanaphol C, Khowsathit P, Ruangdaraganon N. Chromosome 22q11 deletions in patients with conotruncal heart defects. Pediatr Cardiol 2005;26:570-3.

16. McDonald-McGinn DM, Tonnesen MK, Laufer-Cahana A, et al. Phenotype of the 22q11.2 deletion in individuals identified through an affected relative: cast a wide FISHing net! Genet Med 2001;3:23-9.

17. Michaelovsky E, Frisch A, Carmel M, et al. Genotype-phenotype correlation in 22q11.2 deletion syndrome. BMC Med Genet 2012;13:122.

18. Rauch A, Zink S, Zweier C, et al. Systematic assessment of atypical deletions reveals genotype-phenotype correlation in 22q11.2. J Med Genet 2005;42:871-6.

19. Shaikh TH, Kurahashi H, Saitta SC, et al. Chromosome 22-specific low copy repeats and the 22q11.2 deletion syndrome: genomic organization and deletion endpoint analysis. Hum Mol Genet 2000;9:489-501.

20. Saitta SC, Harris SE, Gaeth AP, et al. Aberrant interchromosomal exchanges are the predominant cause of the 22q11.2 deletion. Hum Mol Genet 2004;13:417-28.

21. López JA, Leung B, Reynolds CC, Li CQ, Fox JE. Efficient plasma membrane expression of a functional platelet glycoprotein Ib-IX complex requires the presence of its three subunits. J Biol Chem 1992;267:12851-9.

22. Calverley DC, Yagi M, Stray SM, Roth GJ. Human platelet glycoprotein $\mathrm{V}$ : its role in enhancing expression of the glycoprotein $\mathrm{Ib}$ receptor. Blood 1995;86:1361-7.

23. Berndt MC, Andrews RK. Bernard-Soulier syndrome. Haematologica 2011;96:355-9.

24. Naqvi N, Davidson SJ, Wong D, et al. Predicting 22q11.2 deletion syndrome: a novel method using the routine full blood count. Int J Cardiol 2011;150:50-3.

25. Kato T, Kosaka K, Kimura M, et al. Thrombocytopenia in patients with 22q11.2 deletion syndrome and its association with glycoprotein Ib-beta. Genet Med 2003;5:113-9.

26. Lawrence S, McDonald-McGinn DM, Zackai E, Sullivan KE. Thrombocytopenia in patients with chromosome 22q11.2 deletion syndrome. J Pediatr 2003;143:277-8.
27. Van Geet C, Devriendt K, Eyskens B, Vermylen J, Hoylaerts MF. Velocardiofacial syndrome patients with a heterozygous chromosome 22q11 deletion have giant platelets. Pediatr Res 1998;44:607-11.

28. Liang HP, Morel-Kopp MC, Curtin J, et al. Heterozygous loss of platelet glycoprotein (GP) Ib-V-IX variably affects platelet function in velocardiofacial syndrome (VCFS) patients. Thromb Haemost 2007;98:1298-308.

29. Rosa RF, Rosa RC, Dos Santos PP, Zen PR, Paskulin GA. Hematological abnormalities and 22q11.2 deletion syndrome. Rev Bras Hematol Hemoter 2011;33:151-4.

30. Takahashi K, Kido S, Hoshino K, Ogawa K, Ohashi H, Fukushima Y. Frequency of a 22q11 deletion in patients with conotruncal cardiac malformations: a prospective study. Eur J Pediatr 1995;154:878-81.

31. Amati F, Mari A, Digilio MC, et al. 22q11 deletions in isolated and syndromic patients with tetralogy of Fallot. Hum Genet 1995;95:479-82.

32. Peyvandi S, Lupo PJ, Garbarini J, et al. 22q11.2 deletions in patients with conotruncal defects: data from 1,610 consecutive cases. Pediatr Cardiol 2013;34:1687-94.

33. Williams GD, Bratton SL, Ramamoorthy C. Factors associated with blood loss and blood product transfusions: a multivariate analysis in children after open-heart surgery. Anesth Analg 1999;89:57-64.

34. Despotis GJ, Avidan MS, Hogue CW Jr. Mechanisms and attenuation of hemostatic activation during extracorporeal circulation. Ann Thorac Surg 2001;72:S1821-31.

35. Williams GD, Bratton SL, Riley EC, Ramamoorthy C. Association between age and blood loss in children undergoing open heart operations. Ann Thorac Surg 1998;66:870-5; discussion 875-6.

36. Guay J, Rivard GE. Mediastinal bleeding after cardiopulmonary bypass in pediatric patients. Ann Thorac Surg 1996;62:1955-60.

37. Agarwal HS, Barrett SS, Barry K, et al. Association of blood products administration during cardiopulmonary bypass and excessive post-operative bleeding in pediatric cardiac surgery. Pediatr Cardiol 2015;36:459-67.

38. Tomita-Mitchell A, Mahnke DK, Larson JM, et al. Multiplexed quantitative real-time PCR to detect 22q11.2 deletion in patients with congenital heart disease. Physiol Genomics 2010;42A:52-60.

39. Williams GD, Bratton SL, Riley EC, Ramamoorthy C. Coagulation tests during cardiopulmonary bypass correlate with blood loss in children undergoing cardiac surgery. J Cardiothorac Vasc Anesth 1999;13: 398-404.

40. Greeley WJ, Bushman GA, Kong DL, Oldham HN, Peterson MB. Effects of cardiopulmonary bypass on eicosanoid metabolism during pediatric cardiovascular surgery. J Thorac Cardiovasc Surg 1988;95:842-9. 